University of Wollongong

Research Online

Faculty of Informatics - Papers (Archive)

Faculty of Engineering and Information

Sciences

$1-7-2006$

\title{
Synchronized flicker measurement for flicker transfer evaluation in power systems
}

\author{
S. Perera \\ University of Wollongong, sarath@uow.edu.au \\ Duane Robinson \\ University of Wollongong, duane@uow.edu.au \\ S. Elphick \\ University of Wollongong, elpho@uow.edu.au \\ D. Geddey \\ TransGrid, Sydney \\ N. Browne \\ Integral Energy, Australia
}

See next page for additional authors

Follow this and additional works at: https://ro.uow.edu.au/infopapers

Part of the Physical Sciences and Mathematics Commons

\section{Recommended Citation}

Perera, S.; Robinson, Duane; Elphick, S.; Geddey, D.; Browne, N.; Smith, V.; and Gosbell, V. J.: Synchronized flicker measurement for flicker transfer evaluation in power systems 2006.

https://ro.uow.edu.au/infopapers/420

Research Online is the open access institutional repository for the University of Wollongong. For further information contact the UOW Library: research-pubs@uow.edu.au 


\title{
Synchronized flicker measurement for flicker transfer evaluation in power systems
}

\author{
Abstract \\ Voltage fluctuations caused by rapidly changing loads, such as arc furnaces, can propagate to different \\ parts of a power system. Although the flicker level at its origin can be high, levels that are measured at \\ other sites are subject to attenuation, a process that is influenced by fault levels, transformer \\ impedances, line impedances, and composition of the connected loads. This paper presents the \\ methodology, measurement results, and data analysis in relation to synchronized flicker measurements \\ carried out in a high-voltage (HV)/medium-voltage (MV) power system which contains an arc furnace \\ supplied by a dedicated feeder connected to the HV busbar. The flicker transfer coefficients derived from \\ measurement results clearly indicate that flicker transfer from the arc furnace site to the upstream HV \\ busbar is governed by the fault levels at the two locations. However, the transfer of flicker from the \\ upstream HV busbar to other downstream busbars is dependent on the downstream load composition. \\ These flicker transfer coefficients are vital in the application of methodologies described in many reports \\ and standards in relation to establishing planning levels at various voltage levels and in the allocation of \\ flicker emission to customers.

\section{Disciplines} \\ Physical Sciences and Mathematics

\section{Publication Details} \\ This article was originally published as: Perera, S, Robinson, D, Elphick, D, et al, Synchronized flicker \\ measurement for flicker transfer evaluation in power systems, IEEE Transactions on Power Delivery, July \\ 2006, 21(3), 1477-1482. Copyright 2006 IEEE.

\section{Authors} \\ S. Perera, Duane Robinson, S. Elphick, D. Geddey, N. Browne, V. Smith, and V. J. Gosbell
}




\title{
Synchronized Flicker Measurement for Flicker Transfer Evaluation in Power Systems
}

\author{
Sarath Perera, Member, IEEE, Duane Robinson, Sean Elphick, Don Geddey, Neil Browne, Member, IEEE, Vic Smith, \\ and Vic Gosbell, Member, IEEE
}

\begin{abstract}
Voltage fluctuations caused by rapidly changing loads, such as arc furnaces, can propagate to different parts of a power system. Although the flicker level at its origin can be high, levels that are measured at other sites are subject to attenuation, a process that is influenced by fault levels, transformer impedances, line impedances, and composition of the connected loads. This paper presents the methodology, measurement results, and data analysis in relation to synchronized flicker measurements carried out in a high-voltage (HV)/medium-voltage (MV) power system which contains an arc furnace supplied by a dedicated feeder connected to the HV busbar. The flicker transfer coefficients derived from measurement results clearly indicate that flicker transfer from the arc furnace site to the upstream HV busbar is governed by the fault levels at the two locations. However, the transfer of flicker from the upstream $\mathrm{HV}$ busbar to other downstream busbars is dependent on the downstream load composition. These flicker transfer coefficients are vital in the application of methodologies described in many reports and standards in relation to establishing planning levels at various voltage levels and in the allocation of flicker emission to customers.
\end{abstract}

Index Terms-Flicker, flicker measurement, flicker transfer coefficient.

\section{INTRODUCTION}

$\mathbf{T}$ HERE is an increasing level of interest in power-quality (PQ) monitoring in power systems. Data gathered are useful to transmission and distribution utilities for several purposes including meeting PQ limits stipulated by regulatory bodies, meeting internal quality objectives, assessing new customer connections, and in determining the origin of $\mathrm{PQ}$ problems. Out of the range of PQ disturbances, flicker is not normally a serious problem. However, where there are large fluctuating loads, such as arc furnaces, flicker is a problem of concern as it can propagate to neighboring customer connection points in the power system [1]. The rudimentary theory associated with flicker propagation in power systems is documented in [2]-[6]. These suggest that attenuation of flicker is dependent on several factors including the composition of loads. However, there have been no reports on extensive measurement results which can be used to validate the theoretical arguments. This paper is concerned with a large-scale synchronized flicker mea-

Manuscript received February 9, 2005; revised July 7, 2005. This work was supported by TransGrid. Paper no. TPWRD-00072-2005.

S. Perera, D. Robinson, S. Elphick, V. Smith, and V. Gosbell are with the School of Electrical, Computer and Telecommunications Engineering, University of Wollongong, Wollongong NSW 2522, Australia (e-mail: sarath@uow.edu.au).

D. Geddey is with TransGrid, Sydney, NSW 1235, Australia.

N. Browne is with Integral Energy, Huntingwood, NSW 2148, Australia

Digital Object Identifier 10.1109/TPWRD.2005.864057 surement campaign and subsequent data analysis in relation to a power system that contains a single arc furnace, with a view to establish the flicker levels on a number of busbars located in the vicinity of the arc furnace. The arc furnace site is supplied by a dedicated HV feeder which is connected to an upstream busbar that is also the point of common coupling (PCC) to several other feeders supplying downstream load busbars. The composition of loads connected to these individual feeders is known to be distinctly different in type and, hence, the level of flicker that propagates from the upstream busbar to the individual downstream busbars is expected to be different.

Networks containing multiple significant flicker sources may also require the coordinated measurement of current drawn by the disturbing loads to assist in the estimation of flicker propagation to other parts of the network.

This paper is organized as follows: The basic principles governing downstream to upstream and upstream to downstream flicker propagation in relation to radial power systems are given in Section II. The system in which synchronized flicker measurements have been carried out and the practical issues encountered in the measurements are described in Section III. The results from data analysis are presented and discussed in Section IV. Conclusions are given in Section V.

\section{Principles of Flicker Propagation AND IMPORTANCE OF FLICKER TRANSFER COEFFICIENT}

\section{A. Downstream to Upstream Flicker Transfer}

The flicker that propagates from a major downstream fluctuating source, such as an arc furnace (connected through an HV/MV transformer) to an upstream high-voltage (HV) busbar, is normally established assuming that the flicker severity at a busbar is proportional to its relative voltage change $\Delta V / V$ [2]. For the radial system shown in Fig. 1, the flicker transfer coefficient relating the flicker at the medium-voltage (MV) busbar (that is caused by the downstream arc furnace) with that at the upstream HV busbar can be established using

$$
T_{P_{s t C A}}=\frac{\frac{\Delta V_{A}}{V_{A}}}{\frac{\Delta V_{C}}{V_{C}}}=\left|\frac{Z_{s}}{Z_{s}+Z_{\text {line } 1}+Z_{t f 1}}\right|
$$

where all impedances are referred to the HV side. It is evident from (1) that the flicker at the HV busbar is significantly attenuated as $\left|Z_{s}\right| \ll\left|Z_{\text {line } 1}+Z_{t f 1}\right|$.

\section{B. Upstream to Downstream Flicker Transfer}

The upstream to downstream flicker transfer also can be established using the network shown in Fig. 1. Realizing that 


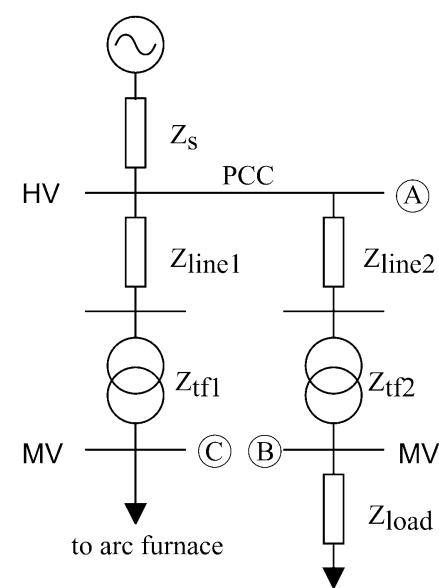

Fig. 1. Simple radial system to illustrate flicker transfer.

under fluctuating conditions the impedance offered by the load is its dynamic value rather than its static value, and assuming that the flicker severity is proportional to the relative fluctuation in the voltage, the flicker transfer coefficient between sites $A$ and $B$ can be shown as [2]

$$
T_{P_{s t A B}}=\frac{\frac{\Delta V_{B}}{V_{B}}}{\frac{\Delta V_{A}}{V_{A}}}=\left|\frac{Z_{\text {load }}^{\prime}}{Z_{l t}+Z_{\text {load }}^{\prime}} \frac{Z_{l t}+Z_{\text {load }}}{Z_{\text {load }}}\right|
$$

where $Z_{\text {load }}$ is the static load impedance, $Z_{\text {load }}^{\prime}$ is the dynamic load impedance, and $Z_{l t}=Z_{\text {line2 }}+Z_{t f 2}$ with all impedances referred to the HV side. For a passive load, its static and dynamic impedances would be approximately equal (i.e., $\left|Z_{\text {load }}\right|=\left|Z_{\text {load }}^{\prime}\right|$ ) whereas for an induction motor, its dynamic impedance is smaller than the static impedance (i.e., $\left.\left|Z_{\text {load }}^{\prime}\right|<\left|Z_{\text {load }}\right|\right)$, leading to $T_{P_{s t A B}}<1.0$.

\section{Importance of Flicker Transfer Coefficient}

As per the IEC Technical Report [7] and the nearly identical Australian/New Zealand Standard [8], the setting of flicker planning levels for various voltage levels requires a knowledge of the flicker transfer coefficient. In particular, when allocating the flicker emission limit to a proposed load, the flicker transfer coefficient plays a vital role. For example, the global flicker emission allowance $G_{P_{s t M V}}$ at an MV busbar that is connected to an upstream HV busbar is given by [7] and [8]

$$
G_{P_{s t \mathrm{MV}}}=\sqrt[3]{L_{P s t \mathrm{MV}}^{3}-T_{P s t \mathrm{HM}}^{3} L_{P s t \mathrm{HV}}^{3}}
$$

where $L_{P s t \mathrm{MV}}$ is the flicker planning level at the MV busbar, $T_{P s t \mathrm{HM}}$ is the flicker transfer coefficient between $\mathrm{HV}$ (i.e., upstream) and the MV (i.e., downstream) system, and $L_{P s t H V}$ is the flicker planning level at the HV busbar. Using the indicative planning levels given in [7] and [8] (i.e., $L_{P s t \mathrm{MV}}=0.8$ and $L_{P s t \mathrm{HV}}=0.9$ ), and considering a unity flicker transfer coefficient from upstream to downstream (i.e., $T_{P s t \mathrm{HM}}=1.0$ ), global short-term flicker emission can be determined as 0.6 for the MV system, whereas with a transfer coefficient of 0.8 , the global short-term flicker emission is 0.78 . Thus, without good knowledge of flicker transfer coefficients, the determination of flicker emission at all voltage levels and, consequently, systematic allocation of flicker emission limits to loads would be difficult.

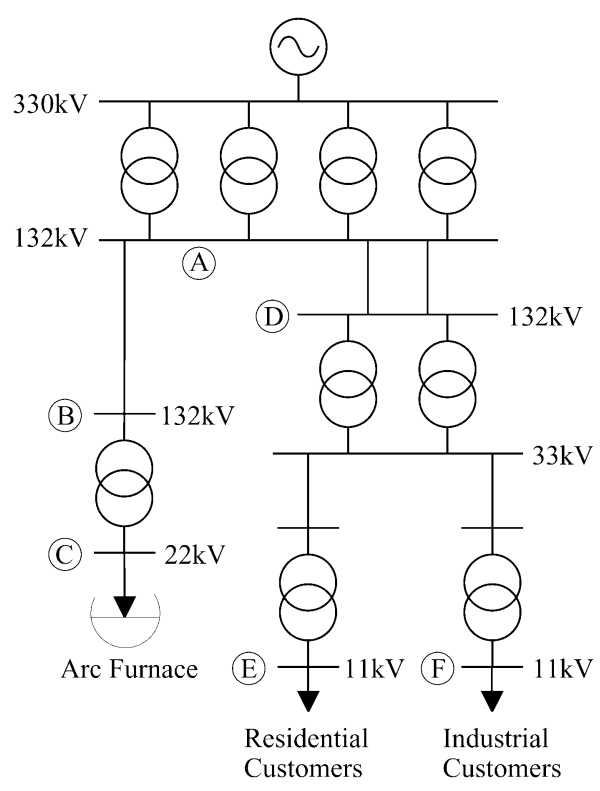

Fig. 2. Simplified schematic diagram of the study system incorporating the arc furnace.

\section{SySTEM DESCRIPTION AND PRACTICAL ISSUES IN RELATION TO FLICKER MEASUREMENTS}

The system in which synchronized flicker measurements was carried out is illustrated by the simplified diagram of Fig. 2. The arc furnace site is supplied by a $132-\mathrm{kV}$ dedicated feeder and the $\mathrm{PCC}$ for this installation is the upstream $132-\mathrm{kV}$ bus (labeled A) at the $330-\mathrm{kV} / 132-\mathrm{kV}$ transmission substation. The nominal rating of the arc furnace is $70 \mathrm{MVA}$. It operates continuously six days a week with the seventh day being a "down day" for maintenance. The approximate value of the fault level on the $132-\mathrm{kV}$ busbar (labeled A) at the upstream transmission substation is 7000 MVA and the fault level on the $22-\mathrm{kV}$ busbar (labeled C) at the arc furnace site is approximately 400 MVA.

Several other 132-kV feeders leaving the transmission substation supply a $132-\mathrm{kV} / 33-\mathrm{kV}$ substation. Two $33-\mathrm{kV}$ feeders, which leave the above $132-\mathrm{kV} / 33 \mathrm{kV}$ substation, supply two distinctly different load bases, one of which is classified as residential (labeled E), and the other is classified as industrial (labeled F).

The flicker that exists on the $33-\mathrm{kV}$ side of the $132-\mathrm{kV} / 33 \mathrm{kV}$ bus is common to both sites $\mathrm{E}$ and $\mathrm{F}$. Using the line and transformer details, the impedances of the systems connecting sites $\mathrm{E}$ and $\mathrm{F}$ to the common $33-\mathrm{kV}$ bus were calculated and found to differ by only approximately $10 \%$. Hence, this difference cannot be identified as a strong reason [as per (2)] for any significant difference in flicker levels between sites $\mathrm{E}$ and $\mathrm{F}$.

Synchronized flicker measurements were carried out using LEM PolyloggerQ instruments (hereafter called Polyloggers). The synchronization of all Polyloggers used in the measurement campaign is achieved by setting up their configuration files using the same laptop computer onsite and by setting the automatic commencement time of the logging to be the same for all Polyloggers running on their internal clocks. Through laboratory testing, it has been verified that the internal clocks of the Polyloggers do not drift significantly enough to affect synchronization considering that $P_{s t}$ is a 10 -min quantity. 

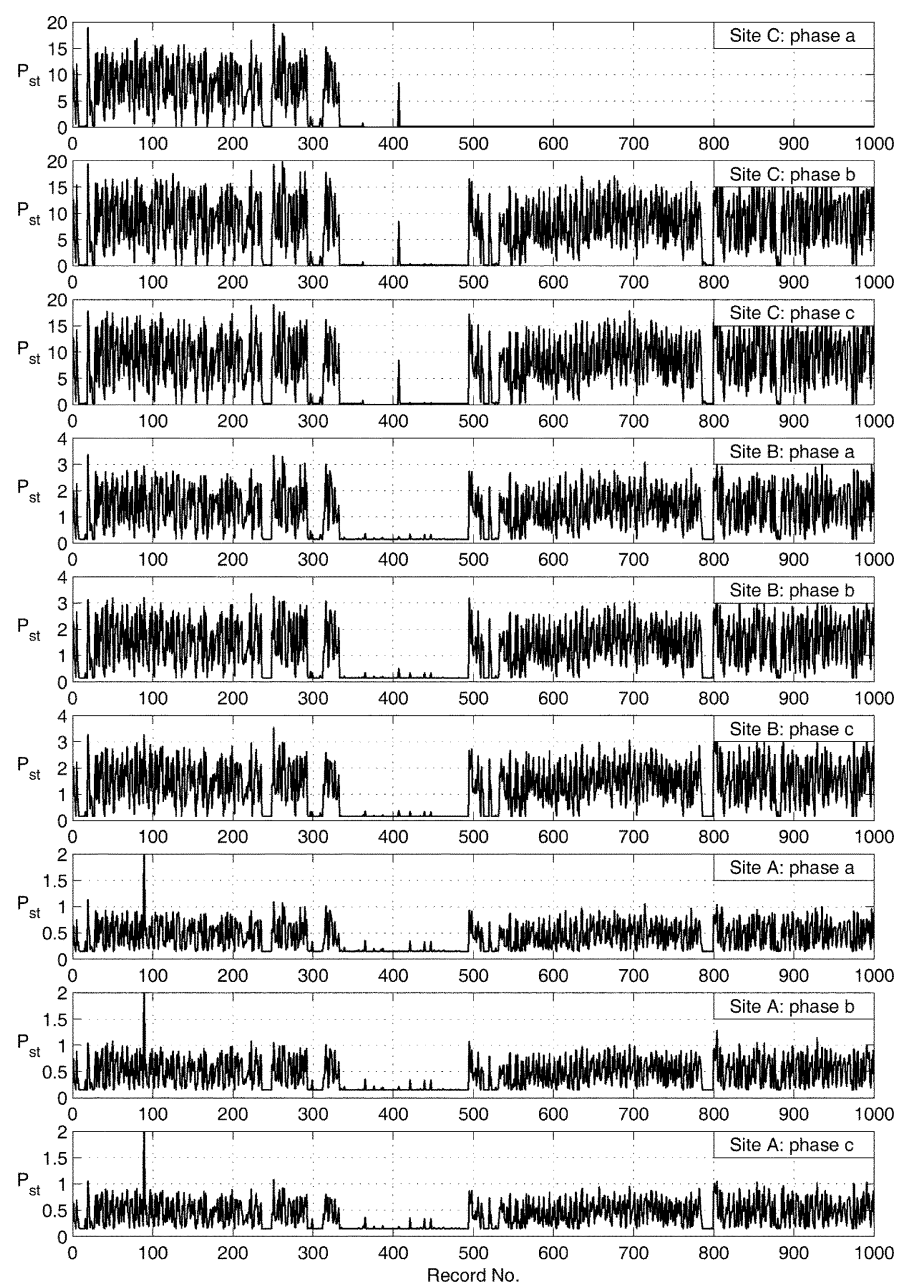

Fig. 3. Recorded $P_{s t}$ values at sites C, B, and A of the study system.

Polyloggers require a four-wire connection to measure all three phases. The locations of these loggers are shown labeled A to $\mathrm{F}$ in Fig. 2. Four-wire voltage transformers (VTs), including a capacitive VT at A and magnetic VTs at $\mathrm{C}, \mathrm{B}$, and D, were available at all sites except at sites $\mathrm{E}$ and $\mathrm{F}$. At sites $\mathrm{E}$ and $\mathrm{F}$, the zone substation auxiliary transformers $(11 \mathrm{kV} / 400 \mathrm{~V})$, which are lightly loaded (about $25 \%$ of nominal rating), were chosen as suitable transducers to measure flicker on the $11-\mathrm{kV}$ busbar, providing the four-wire connections required for the polyloggers.

Sites $\mathrm{E}$ and $\mathrm{F}$ are equipped with ripple injection equipment connected to the $11-\mathrm{kV}$ side for downstream load management (hot water and street lighting). The induction motor driving the high-frequency generator of this equipment is supplied by the station auxiliary transformer and, hence, the startup transient of the motor has an impact on local flicker readings that require attention during data analysis. This aspect will be discussed in further detail in Section IV. The measurements were carried out over a week as recommended in [7] and [8] which included the "down day" of the arc furnace.

\section{DATA ANALYSIS AND RESUlts}

\section{A. General Discussion on Observations at Sites $C, B$, and $A$}

The variation of $P_{s t}$ values over the period of monitoring for sites C, B, and A (of Fig. 2) is illustrated by Fig. 3. The arc fur- nace down period is clearly evident in all graphs. Several abnormalities that can be observed in these graphs will be explained in this section.

In general, the propagation of the arc furnace flicker to the upstream PCC (site A), with a substantial level of attenuation, is clearly evident. In relation to site $\mathrm{C}$, the abnormal single high value of flicker reading during the arc furnace down period and the absence of flicker readings for phase $a$ in the latter half of the monitoring period was caused by powering down of the panel on which the Polylogger was connected. It is clearly evident that the energization of the panel causes a sudden change in voltage leading to a high $P_{s t}$ value, despite the fact that the arc furnace was not operational. For an unknown reason, phase $a$ of the Polylogger stayed disconnected over the latter part of the monitoring period during which the arc furnace was operational.

Site A shows a single abnormally high $P_{s t}$ value in the early part of the monitoring period. Investigations revealed that the cause of this was an upstream voltage sag, which is expected to propagate to all parts of the system being monitored. At site B, the effect of the voltage sag is not very prominent (although it is faintly visible) mainly due to the high levels of flicker caused by the arc furnace itself. As this single high $P_{s t}$ value is caused by an external event (i.e., not by the arc furnace) and is common to all measurement sites, for further correlation purposes, the corresponding $P_{s t}$ values will be removed from the data collected for all sites.

\section{B. General Discussion on Observations at Sites D, E, and F}

The variation of $P_{s t}$ values over the monitoring period for sites D, E, and F (of Fig. 2) is illustrated by Fig. 4. Flicker readings at site $\mathrm{D}$ are seen to align well with those at site A (shown in Fig. 3) with respect to the daily pattern of flicker level activity (144 records equates to $24 \mathrm{~h}$ ). As expected, the effect of the upstream voltage sag is clearly visible at $\mathrm{D}$ and downstream at $\mathrm{E}$ and F. As highlighted in Section III, the flicker readings at sites $\mathrm{E}$ and $\mathrm{F}$ are significantly affected by local disturbances caused by the ripple injection system and, hence, cannot be easily correlated with those at D. It can also be noticed that the daily flicker patterns from local disturbances at $\mathrm{E}$ and $\mathrm{F}$ do not seem to propagate to the upstream point $\mathrm{D}$ in any attenuated form.

Realizing that local disturbances caused by the ripple injection systems result in flicker readings which are well in excess of what can propagate from the arc furnace operation, it is possible to remove all abnormally high $P_{s t}$ values from the data collected for sites $\mathrm{E}$ and $\mathrm{F}$ and the corresponding time synchronized values from those for site D. Accordingly, all values of $P_{s t}>1.2$ from sites $\mathrm{E}$ and $\mathrm{F}$ data sets and corresponding time-stamped values from all other sites have been removed for the correlation analysis. Following this filtering operation, flicker levels at both $\mathrm{E}$ and $\mathrm{F}$ are seen to align quite well with those at $\mathrm{D}$, as shown by the daily pattern of flicker level activity in Fig. 5 for phase $a$ only and an enlargement of a section of this pattern in Fig. 6. A similar alignment was found for phases $b$ and $c$.

The disturbance at $\mathrm{F}\left(P_{s t}=1.02\right)$ during the arc furnace down period was indicated in Fig. 5, although seemingly aligning with a similar disturbance at $\mathrm{C}$ in Fig. 3, is an isolated local event which remained after filtering. As this disturbance 


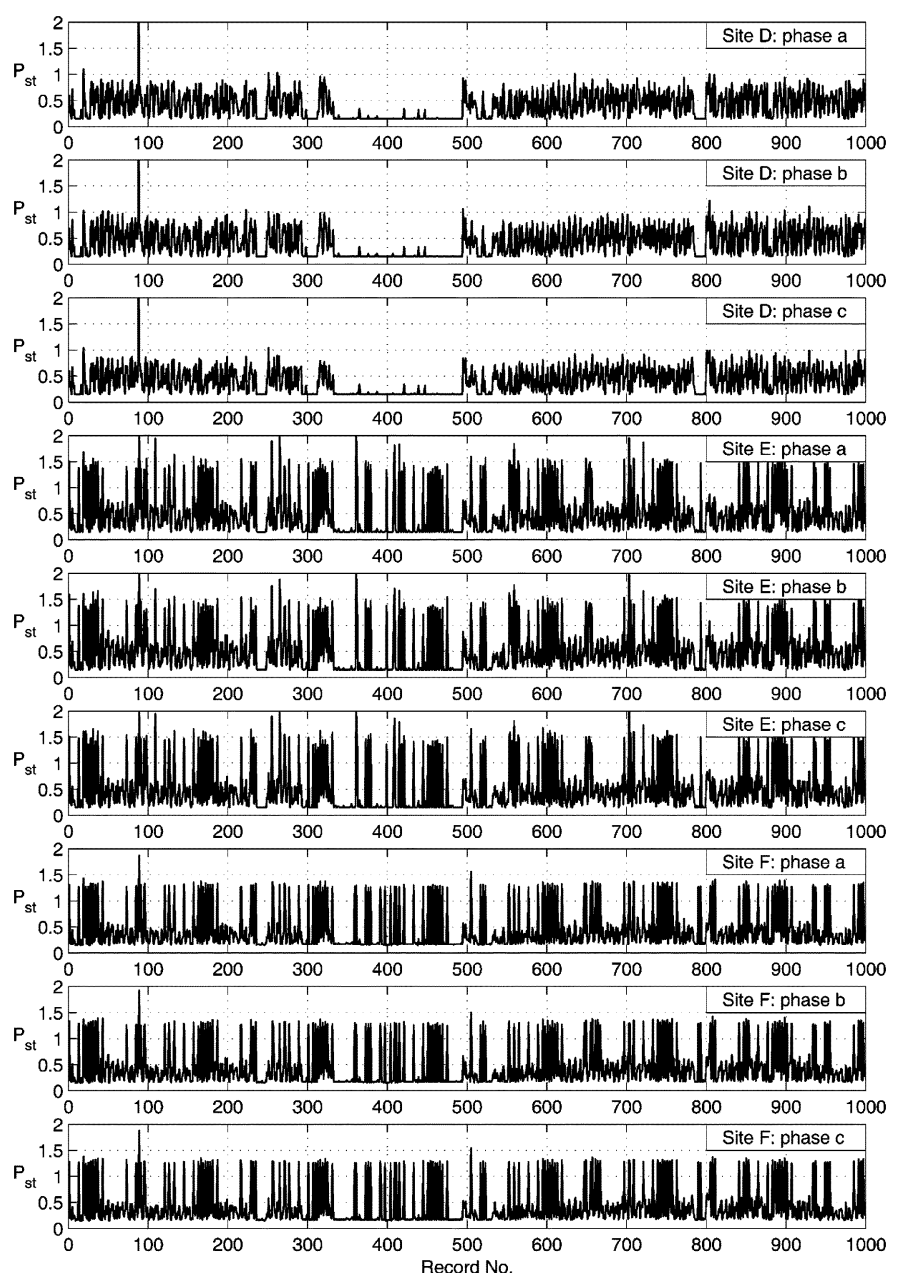

Fig. 4. Recorded $P_{s t}$ values at sites D, E, and F of the study system.

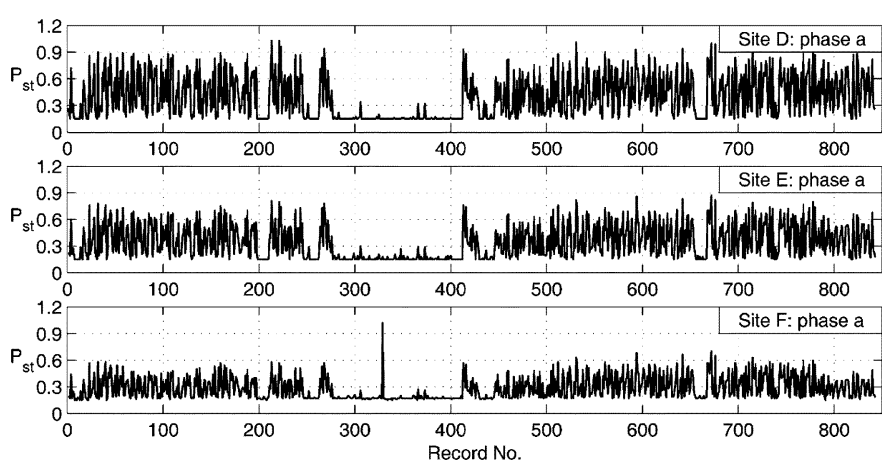

Fig. 5. Recorded $P_{s t}$ values for phase $a$ at sites D, E, and F of the study system after filtering.

is a single event; it has an insignificant bearing on the overall correlation.

Sites with multiple significant sources of flicker may require more extensive filtering methods to establish the required correlation for determining flicker transfer coefficients.

\section{Correlation of Flicker at Monitored Sites}

Results presented in the above two sections allowed correlation of the synchronously measured $P_{s t}$ values in a visual manner. By adopting scatter plots, these flicker values can be more effectively correlated, thereby allowing the identification of flicker transfer coefficients.

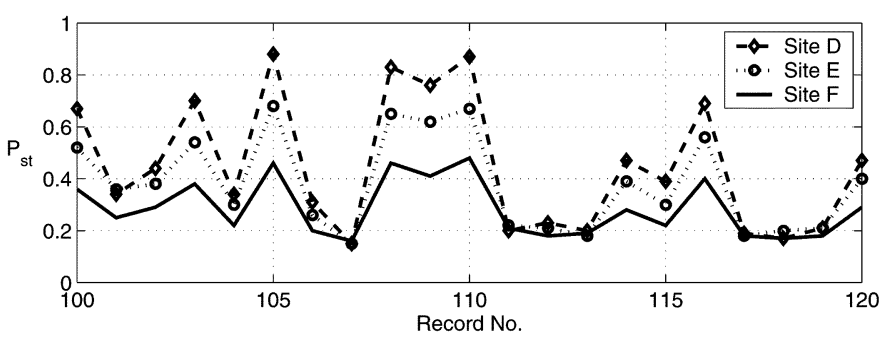

Fig. 6. Recorded $P_{s t}$ values for phase $a$ at sites D, E, and F of the study system after filtering (records 100 to 120 only).
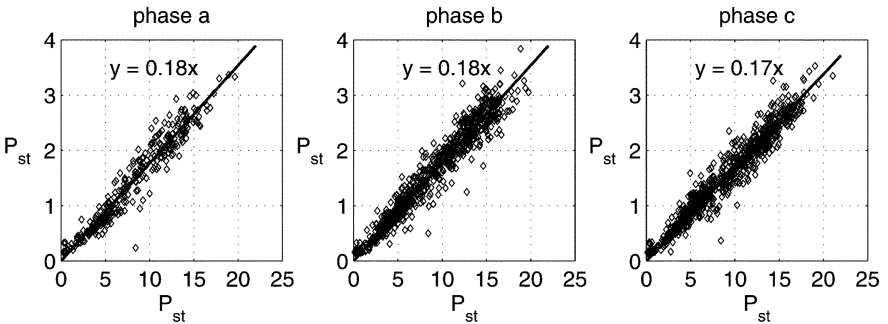

Fig. 7. Scatter plots of $P_{s t}$ values of site B versus site C.
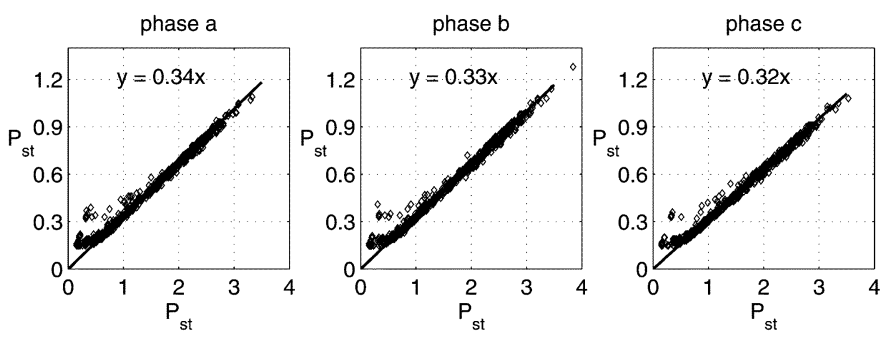

Fig. 8. Scatter plots of $P_{s t}$ values of site A versus site B.

Fig. 7 shows the scatter plots for sites $\mathrm{C}$ and $\mathrm{B}$. The linear regression lines shown have been forced to pass through zero, from which it is possible to determine the flicker transfer coefficient. The slopes of these lines indicate that site B flicker is attenuated by a factor of nearly $5.7(=1 / 0.18)(0.18$ being the average of the three slopes). Using the arc furnace transformer details, the fault level at site B, and by applying (1), the flicker attenuation coefficient is calculated to be 0.17 , which is in good agreement with the scatter plots of Fig. 7.

Fig. 8 gives the scatter plots for sites $\mathrm{B}$ and $\mathrm{A}$. The average value of 0.33 for the slopes of the regression lines indicates further attenuation as the flicker due to arc furnace propagates to the upstream PCC. Based on the two corresponding fault levels (2400 and 7000 MVA approximately), the flicker transfer coefficient calculated by using (1) is 0.35 . Again, there is very close agreement between what is predicted by the measurements and that obtained from the ratio of fault levels.

Fig. 9 illustrates the scatter plots for sites A and D where only very little attenuation is seen with an average flicker transfer coefficient of 0.96 .

Fig. 10 illustrates the scatter plots obtained for sites D and E (latter classified as residential) before filtering the local disturbances that were caused by the ripple injection system. It is evident that despite the presence of the above disturbances, there are a significant number of $P_{s t}$ values that are present at site $\mathrm{E}$ that correlate well with the upstream site $\mathrm{D} P_{s t}$ values which are essentially caused by the arc furnace. 

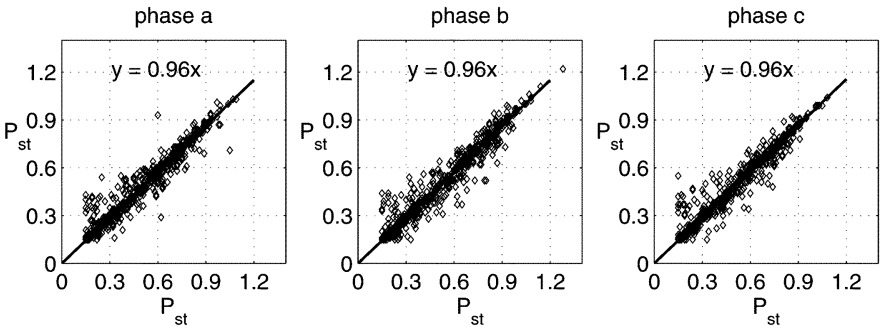

Fig. 9. Scatter plots of $P_{s t}$ values of site D versus site A.
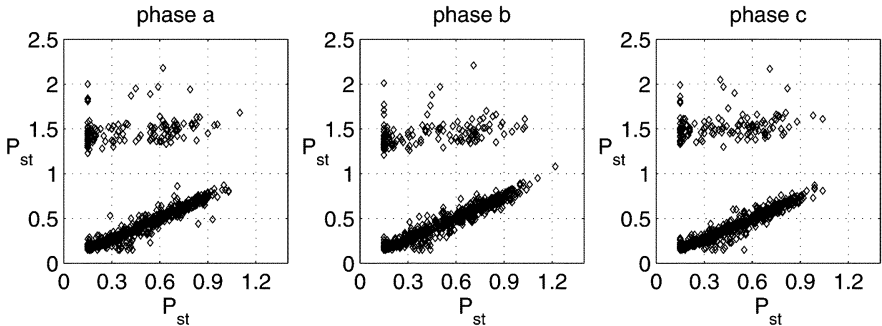

Fig. 10. Scatter plots of $P_{s t}$ values of site $\mathrm{E}$ versus site D before filtering of values due to ripple injection equipment.
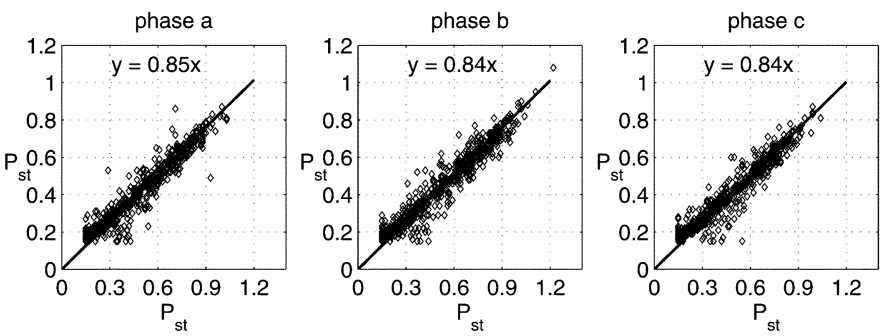

Fig. 11. Scatter plots of $P_{s t}$ values of site E versus site D after filtering of values due to ripple injection equipment.
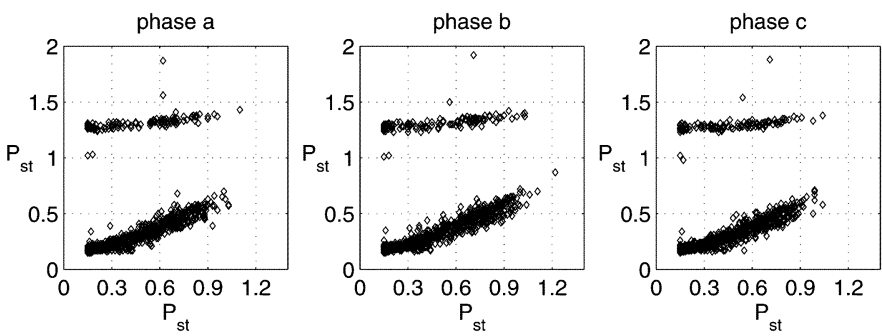

Fig. 12. Scatter plots of $P_{s t}$ values of site $\mathrm{F}$ versus site $\mathrm{D}$ before the filtering of values due to ripple injection equipment.

The scatter plots obtained after filtering the $P_{s t}$ values arising as a result of the local events are shown in Fig. 11 from which the average value of the flicker transfer coefficient between $\mathrm{D}$ and $\mathrm{E}$ is obtained as 0.84 .

Fig. 12 represents the case as for Fig. 10 for sites D and $F$ (latter classified as industrial). Again, there are a sufficient number of arc-furnace-related $P_{s t}$ values that correlate well.

The scatter plots obtained after filtering the $P_{s t}$ values arising as a result of the above abnormal events are shown in Fig. 13, from which the value of the flicker transfer coefficient between $\mathrm{D}$ and $\mathrm{F}$ is obtained as 0.66 .

The difference in the two flicker transfer coefficients calculated above, 0.84 (D to E) and 0.66 (D to F), suggests that the industrial load bases help attenuate the flicker more than residential load bases. This observation is also supported by the simple formulation (2)
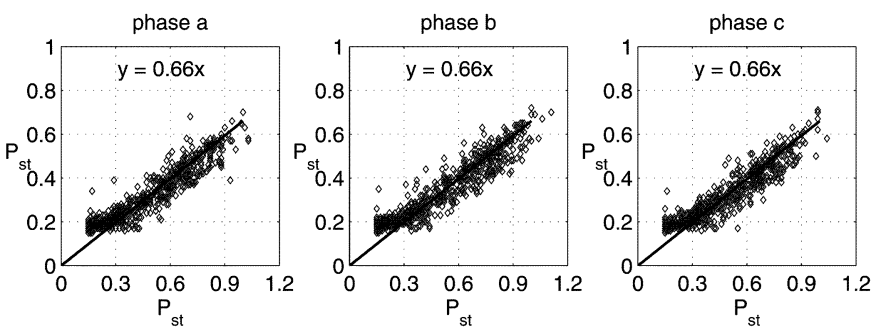

Fig. 13. Scatter plots of $P_{s t}$ values of site $\mathrm{F}$ versus site D after filtering of values due to ripple injection equipment.

TABLE I

MAXIMUM SHORT-TERM AND LONG-TERM 99\% AND 95\% VALUES OF FLICKER AND THEIR RATIOS FOR SITE A BEFORE AND AFTER FILTERING

\begin{tabular}{c|c|c|c|c}
\hline \multirow{2}{*}{} & \multicolumn{2}{|c|}{$P_{s t}$} & \multicolumn{2}{c}{$P_{l t}$} \\
\cline { 2 - 5 } & before & after & before & after \\
\hline $95 \%$ value & 0.92 & 0.92 & 0.71 & 0.70 \\
\hline $99 \%$ value & 1.04 & 1.02 & 1.14 & 0.75 \\
\hline \hline $99 \% / 95 \%$ ratio & 1.13 & 1.11 & 1.61 & 1.07 \\
\hline
\end{tabular}

\section{Establishment of Statistical Values of $P_{\text {st }}$}

As per [7] and [8], it is required that from the flicker measurements carried out over a week, $95 \%$ and $99 \%$ cumulative probability values of $P_{s t}$ and $P_{l t}$ values can be established and compared against planning levels. It is also suggested that if the ratio of $99 \%$ and $95 \%$ values is greater than 1.3 , the reasons for such discrepancy need to be examined (e.g., thunderstorms), and flicker readings due to abnormal events need to be removed before evaluating the probability values. Although polyloggers provide $P_{l t}$ values in addition to $P_{s t}$ values when abnormal data, such as the above are filtered, it becomes necessary to manually recalculate the $P_{l t}$ values. To illustrate the importance of the above data filtering, consider the effect of the voltage sag for site A (Fig. 3) leading to an abnormally high $P_{s t}$ value. This value can have a significant impact on the $P_{l t 99 \%}$ value which is greater than the $P_{s t 95 \%}, P_{l t 95 \%}$, or $P_{s t 99 \%}$ values. To briefly illustrate this, the maximum values of flicker across all phases can be used (flicker observed across phases was found to have small differences). These flicker values and the ratios $P_{s t 99 \%} / P_{s t 95 \%}$ and $P_{l t 99 \%} / P_{l t 95 \%}$ before and after filtering the single high $P_{s t}$ value are tabulated in Table I. It is clearly evident that the filtering of the flicker readings due to abnormal events is crucial in evaluating a site for flicker compliance.

The evaluation of cumulative probability values of flicker for sites $\mathrm{E}$ and $\mathrm{F}$ is complicated by the fact that the significant number of abnormal $P_{s t}$ values that are caused by the local ripple injection equipment have been removed in addition to that caused by the upstream voltage sag. Using the already established flicker transfer coefficients and the flicker readings at site D (upstream bus of sites E and F), it is possible to reconstruct the missing $P_{s t}$ values for sites $\mathrm{E}$ and $\mathrm{F}$, thus enabling the calculation of $95 \%$ and $99 \%$ flicker values.

Following the methodologies given above, the calculated maximum cumulative probability values of flicker across all phases are given in Table II illustrating the general nature of the arc furnace flicker propagation in the study system.

\section{CONCLUSION}

Synchronised flicker measurements can be undertaken using a number of suitable flicker measuring instruments. Such sur- 
TABLE II

MAXIMUM OF SHORT-TERM AND LONG-TERM 99\% AND 95\% VALUES OF FLICKER OF THE STUDY SYSTEM

\begin{tabular}{c|c|c|c}
\hline Site & Probability value & $P_{s t}$ & $P_{l t}$ \\
\hline \hline $\mathrm{C}$ & $95 \%$ & 15.8 & 13.0 \\
\cline { 2 - 4 } & $99 \%$ & 17.7 & 15.5 \\
\hline \multirow{2}{*}{$\mathrm{B}$} & $95 \%$ & 2.78 & 2.14 \\
\cline { 2 - 4 } & $99 \%$ & 3.10 & 2.23 \\
\hline \multirow{2}{*}{$\mathrm{A}$} & $95 \%$ & 0.9 & 0.70 \\
\cline { 2 - 4 } & $99 \%$ & 1.02 & 0.75 \\
\hline \multirow{2}{*}{$\mathrm{D}$} & $95 \%$ & 0.89 & 0.68 \\
\cline { 2 - 4 } & $99 \%$ & 1.00 & 0.73 \\
\hline \multirow{2}{*}{$\mathrm{E}$} & $95 \%$ & 0.73 & 0.57 \\
\cline { 2 - 4 } & $99 \%$ & 0.83 & 0.63 \\
\hline \multirow{2}{*}{$\mathrm{F}$} & $95 \%$ & 0.57 & 0.46 \\
\cline { 2 - 4 } & $99 \%$ & 0.65 & 0.51 \\
\hline
\end{tabular}

veys can be conducted simply provided some care is applied in relation to system abnormalities. The practical problems encountered in measuring the flicker were highlighted and the solutions adopted were detailed.

The results of data analysis were presented, from which it is clear that flicker propagating from a downstream to an upstream point can be established using the corresponding fault levels, whereas upstream to downstream flicker transfer is very dependent on the downstream load composition. In the case investigated, the residential load base gave a flicker transfer coefficient of 0.84 , whereas the industrial load base gave a flicker transfer coefficient of 0.66. Such differences in flicker transfer coefficients can become important in allocating flicker emission to fluctuating loads.

The methodologies adopted in relation to the filtering of abnormal data and data reconstruction in determining the statistical values of $P_{s t}$ for the various sites of the study system were also described.

\section{ACKNOWLEDGMENT}

Assistance received from Integral Energy is greatly appreciated. The authors would like to thank TransGrid for the initiatives taken to undertake the study.

\section{REFERENCES}

[1] A. Robert and M. Couvreur, "Arc furnace flicker assessment and prediction," in Proc. 12th Int. Conf. Electricity Distribution, vol. 2, May 17-21, 1993, pp. 2.2/1-2.2/6.

[2] E. De Jaeger, G. Borloo, and W. Vancoetsem, "Flicker transfer coefficients from HV to MV and LV systems," in Proc. 14th Int. Conf. Electricity Distribution, Session 2. Birmingham, U.K., Jun. 1997, pp. 101-102.

[3] H. Renner and M. Sakulin, "Flicker propagation in meshed high voltage networks," in Proc. 9th Int. Conf. Harmonics and Quality of Power, vol. 3, Oct. 1-4, 2000, pp. 1023-1028.

[4] M. C. Simoes and S. M. Deckmann, "Flicker propagation and attenuation," in Proc. 10th Int. Conf. Harmonics and Quality of Power, vol. 2, Oct. 6-9, 2002, pp. 644-648.

[5] B. N. Ramos, J. F. M. Garcia, and M. P. Donsion, "Study of flicker generation and transmission in interconnected electric grids," in Proc. 10th Int. Conf. Harmonics and Quality of Power, vol. 1, Oct. 6-9, 2002, pp. 66-70.

[6] S. Tennakoon, L. Perera, D. Robinson, and S. Perera, "Flicker transfer in radial power systems," in Proc. Australasian Universities Power Engineering Conf., Brisbane, Australia, Sep. 2004, Paper 190, pp. 190-190.

[7] Electromagnetic Compatibility (EMC)_Part 3: Limits-Section 7: Assessment of Emission Limits for Fluctuating Loads in MV and HV Power Systems-Basic EMC Publication, IEC/TR 61 000-3-7:2001, Ed. 1.
[8] Electromagnetic Compatibility (EMC)—Limits_Assessment of Emission Limits for Fluctuating Loads in MV and HV Power Systems (IEC 61 000-3-7:1996, MOD), AS/NZS 61 000.3.7:2001.

Sarath Perera (M'96) received the B.Sc.(Eng.) degree in power from the University of Moratuwa, Sri Lanka, in 1974, the M.Eng.Sc. degree from the University of New South Wales, Australia, in 1978, and the Ph.D. degree from the University of Wollongong, Wollongong, Australia, in 1988.

He was a Lecturer for 12 years with the University of Moratuwa. Currently, he is a Senior Lecturer with the University of Wollongong and is the Technical Director of the Integral Energy Power Quality and Reliability Center, University of Wollongong. His research interests are in power quality.

Duane Robinson received the B.E.(Hons.) degree in electrical engineering and the Ph.D. degree in harmonics from the University of Wollongong, Wollongong, Australia.

Currently, he is a Senior Lecturer with the University of Wollongong and was with BHP Steel, Port Kembla, Australia, for seven years. He is also with the Integral Energy Power Quality and Reliability Center, University of Wollongong. His research interests include power quality and reliability.

Dr. Robinson is a member of Engineers Australia.

Sean Elphick received the B.E.(Hons.) degree from the University of Wollongong, Wollongong, Australia, in 2001.

Currently, he is with the Strategic Partnerships with Industry-Research and Training Scheme (SPIRT) with the Integral Energy Power Quality and Reliability Center at the University of Wollongong.

Don Geddey received the B.Sc., B.E., and Ph.D. degrees from the University of Sydney, Sydney, Australia, in 1968, 1970, and 1980, respectively.

Currently, he is the System Investigations Manager with TransGrid, the transmission utility in the eastern Australian state of New South Wales. His work includes system design studies in the areas of system dynamics, supply quality, and electromagnetic transients.

Neil Browne (M'89) received the B.E. degree from the University of New South Wales, New South Wales, Australia, in 1976.

Currently, he is an Engineer with Integral Energy's System Development Branch, Huntingwood, Australia. He is involved in protection policy, operational analysis, and power-quality control and monitoring.

Mr. Browne is a member of Engineers Australia.

Vic Smith received the B.E. degree with NSW Institute of Technology, Sydney, Australia, in 1981, the M.Sc. degree from the University of Manchester Institute of Science and Technology (UMIST), Manchester, U.K., and the Ph.D. degree from Arc Studies Laboratory of Sydney University, Sydney, in 1995.

He was with the Sydney County Council and was a Researcher with the High Power Testing and Arc Studies Laboratory of Sydney University. In 1997, he was a Research Engineer with the Integral Energy Power Quality and Reliability Center at the University of Wollongong, Wollongong, Australia.

Vic Gosbell (M'75) received the B.E. and Ph.D. degrees from the University of Sydney, Sydney, Australia, in 1966 and 1971, respectively.

He has held academic positions with the University of Sydney and the University of Wollongong, Wollongong, Australia, where he is Foundation Professor of Power Engineering and Technical Advisor of the Integral Energy Power Quality and Reliability Center. He is currently working on harmonic management and power-quality monitoring.

Dr. Gosbell is a Fellow of Engineers Australia. 